\title{
Keterlibatan Alumni Universitas Tarumanagara dalam Pemilihan Presiden Melalui Media Sosial Instagram
}

\author{
Maria Steffi Gunadi, Ahmad Junaidi \\ mariasteffigunadi@gmail.com,ahmadd@fikom.untar.ac.id \\ Fakultas Ilmu Komunikasi Universitas Tarumanagara
}

\begin{abstract}
Currently Instagram as a new media, has often been used as a political propaganda tool, both in the world and in Indonesia. Instagram as social media is used to lead to democracy, which is sometimes not necessarily similar to actual conditions. However, there are still many people who still believe in information obtained through Instagram so that the formation of political communication is the involvement of the community in terms of politics so that the formation of political efficacy. This paper was made to arouse the public more wisely in issuing opinions through social media, especially in political choice.
\end{abstract}

Keywords: New media, Social Media, Democracy, Political Communication, Political Efficacy, Political Involvement

\begin{abstract}
Abstrak
Saat ini Instagram sebagai new media, kerap digunakan sebagai alat propaganda politik, baik di dunia maupun di Indonesia. Instagram sebagai media sosial digunakan untuk menggiring demokrasi, yang terkadang belum tentu serupa dengan kondisi sebenarnya. Namun demikian, masih banyak orang yang masih mempercayai informasi yang diperoleh melalui Instagram sehingga terbentuk komunikasi politik yang merupakan keterlibatan para masyarakat dalam hal politik, atau efikasi politik. Tulisan ini dibuat untuk menggugah masyarakat semakin bijak dalam mengeluarkan pendapat melalui media sosial, terutama dalam pilihan politik.
\end{abstract}

Kata Kunci: media baru, media sosial, demokrasi, komunikasi politik, efikasi politik, keterlibatan politik

\section{Pendahuluan}

Penggunaan akun media sosial Instagram telah menjadi salah satu alat penyampaian informasi kepada masyarakat luas. Ini menjadi seolah lahan basah bagi partai politik dalam menyampaikan pesan politik terhadap masyarakat. Apalagi saat ini, Indonesia menggelar pemilihan Presiden 2019. Para alumni Universitas Tarumanagara juga ikut tampil berpartisipasi dalam pemilihan Presiden Indonesia 2019. Keikutsertaan alumni Universitas Tarumanagara dalam pemilihan Presiden periode ini dengan mengunggah pendapat masing-masing di Instagram yang mereka dapatkan dari beberapa akun Instagram para partai politik. Indonesia merupakan salah satu negara yang memberikan kebebasan berpendapat kepada warga Indonesia sendiri. Pendapat ini dapat dibuktikan dengan adanya UUD 45 Pasal 28E ayat 3 yaitu "setiap orang berhak atas kebebasan berserikat, berkumpul dan mengeluarkan pendapat".

Pada tahun 1990 Mark Poster (2009:413) meluncurkan buku besarnya, The Second Media Age, yang menandai periode baru dimana teknologi interaktif dan komunikasi jaringan, khususnya dunia maya akan mengubah masyarakat. Media baru 
juga mengandung kekuasaan dan batasan, kerugian dan keuntungan, dan kebimbangan. Sebagai contoh, media baru mungkin memberikan penggunaan yang terbuka dan fleksibel, tetapi dapat juga menyebabkan kebingungan dan kekacauan. Menurut Rudiantara, Menteri Komunikasi dan Informatika RI (2017:151), jika digunakan dengan benar, media sosial dan teknologi digital akan menjadi berkah bagi bangsa Indonesia. Oleh karena itu, tidak diperkenankan terdapat konten negatif di dalamnya. Media sosial perlu dipenuhi dengan hal-hal berguna, membagikan informasi yang telah disaring kebenaran dan manfaatnya. Demokrasi dalam pemahaman Bahasa Yunani Kuno berarti kekuasaan yang berada di tangan rakyat. Demokrasi berfokus pada dua hal penting yang saling berkaitan, yakni representasi (perwakilan) dan partisipasi (2016:53). Dari catatan yang dibuat oleh Zakaria (2003.2016:55) disebutkan bahwa hingga tahun 1900 belum ada satupun demokrasi, yaitu suatu negara yang diatur oleh suatu pemerintahan dari hasil pemilihan umum dimana para warga negaranya yang sudah dewasa menggunakan hak pilihnya (vote).

Ilmuwan politik Mark Roefolfs (2015:8) mengatakan politik adalah pembicaraan atau lebih tepat, kegiatan politik (berpolitik) adalah berbicara. Proses opini (Nimmo, 2015:12) adalah hubungan atau kaitan antara kepercayaan, nilai, dan usul yang dikemukakan oleh perseorangan di depan umum dan kebijakan yang dibuat oleh pejabat terpilih dalam mengatur perbuatan sosial dalam situasi konflik, yakni dalam politik. Dalam proses itu ada tiga tahap: Pertama, konstruksi personal, yaitu tahap dimana individu mengamati segala sesuatu menginterpretasikannya, dan menyusun makna objek-objek politik secara sendiri dan subjektif. Kedua, konstruksi sosial, yaitu tahap menyatakan opini pribadi di depan umum. Ada tiga bentuk pernyataan ini yaitu: pemberian dan penerimaan opini pribadi didalam kelompok sosisal yang menghasilkan opini kelompok; jika orang mengungkapkan pandangannya bukan melalui kelompok teroganisasi melainkan melalui kebebasan pribadi yang membentuk opini rakyat; opini massa pada umumnya merupakan ungkapan pada pandangan yang baur dan tak terorganisir, yang sering disimbolkan seagai budaya, konsensus, dan apa yang oleh para politikus dengan fasih disebut "opini publik"; konstruksi politk, yaitu tahap menghubungkan opini publik, opini rakyat, dan opini massa dengan kegiatan para pejabat publik (eksekutif, legislator, dan hakim) yang sama bertanggung jawab atas pemrakarsaa, perumusan, penerimaan, penerapan, penginterpretasian, dan penilaian kebijakan-kebijakan.

Alumni merupakan bagian yang akan selalu ada di setiap siklus pendidikan. Universitas Tarumanagara tentunya memiliki banyak sekali alumni dari setiap tahun dan jurusannya di karenakan telah berdiri dari 1 Oktober 1959. Setiap para alumni memiliki pemikiran dan pendapat masing-masing yang beberapa ada menyampaikan kepada public dan ada juga yang disimpan saja dengan berbagai alasan.

Partisipasi politik adalah masyarakat yang telah menjadi isu dan kajian menarik baik pemerintahan, para akademisi, praktisi, maupun professional, karena partisipasi politik masyarakat memiliki hubungan erat dengan keterlibatan masyarakat dalam upaya menciptakan iklim demokrasi di Indonesia. Menurut Almond dan Verba dalam bukunya "the civic culture" (2016:1), kelompok masyarakat dan masyarakat pada umumnya untuk hidup berdampingan dalam situasi demokrasi yang stabil. Pemikiran Almond dan Verba memiliki kemiripan dengan pemikiran Emile Durkheim yang juga mengusung teori struktur fungsional masyarakat yang mencoba membuat kajian (inquiry) tentang bagaimana masyarakat dapat mempertahankan unitas masyarakat tanpa adanya konflik (2016:1). Dengan demikian parokialisme dalam sistem politik yang diferensiatif lebih bersifat afektif dan orientatif dari pada kognitifnya. Penelitian 
yang dilakukan Reddel dan Woolcock (2003.2016:10) menggambarkan bahwa terdapat perkembangan dewasa ini khususnya negara-negara yang menganut sistem demokratis di dunia ternyata perhatian pemerintah telah meningkat dan patut diapresiasi karena pemerintah telah memberikan perhatian terhadap partisipasi politik masyarakat, dan menumbuhkan kepemerintahan demokratis yang mencakup prinsip dan metode peningkatan partisipasi masyarakat. Buku Emile Durkheim (1893.2016:1) yang berjudul "The Division of Labor in Society" menjelaskan secara khusus bagaimanafungsi sosial masyarakat itu saling berhubungan ("corresponds") satu dengan yang lainnya.

Budaya politik parokial biasanya terdapat dalam sistem politik tradisional dan sederhana, dengan ciri khas spesialis masih sangat kecil, sehingga pelaku-pelaku politik belumlah memiliki tugas.

Efikasi politik merupakan rasa individu dalam bidang politik. Perasaan bahwa tindakan politik atau partisipasi politik individu yang dapat memiliki pengaruh terhadap proses politik. Menurut Michael E Morrel (2003) yaitu meliputi kualifikasi atau kemampuan diri seseorang untuk berpartisipasi dalam politik memahami isu-isu aktual politik, perasaan bisa bekerja dengan baik di instansi publik seperti orang lain, kemampuan memberikan informasi tentang politik. Ada beberapa faktor yang mempengaruhi seseorang dalam politik.

Menurut Morrel (2003) yang menemukan bahwa efikasi politik berkorelasi sangat kuat dengan keikutsertaan psikologis. Menururt Matulessy (2008) menjelaskan variable political efficacy berpengaruh terhadap muculnya partisipasi dalam gerakan sosial. Sedangkan teori menurut Catellani (Semin \& Fiedler, 1996) juga menemukan bahwa aktivitas politik seseorang salah satunya di pengaruhi oleh rasa berperan dalam bidang politik. Efikasi politik dalam pandangan tradisional sebagai persepsi yang dimiliki seseorang tentang dirinya dan kemampuan untuk mempengaruhi politik pada situasi tertentu (Ramadhani, 2008).

Menurut Muhatdi (2009) bahwa kenaikan jumlah golput di picu meluasnya perasaan aliansi politik bahwa pemilihan umum sudah tidak terkait dengan kepentingan pragmatis pemilih. Ada faktor-faktor yang mempengaruhi keterlibatan psikologis dalam politik. Keterlibatan politik memiliki tiga yaitu political engagement, political trust, dan efikasi politik menurut Mangum (2003).

\section{Metode Penelitian}

Penulis dalam penelitian ini menggunakan metode penelitian kualitatif. Menurut Sugiyono (2011:8), metode penelitian kualitatif adalah penelitian yang berlandaskan pada filsafat post positivism, digunakan untuk meneliti pada kondisi obyek alamiah,(sebagai lawannya eksperimen) di mana peneliti adalah sebagai instrumen kunci, pengambilan sampel sumber data dilakukan secara purposive dan snowball, analisis data bersifat induktif atau kualitatif, dan hasil penelitian kualitatif lebih menekankan makna dari pada generalisasi.

Penelitian kualitatif tidak menggunakan statistic, tetapi melalui pengumpulan data, analisis kemudian diinterpretasikan. Penelitian kualitatif ini penelitian yang menekankan pada pemahaman mengenai masalah-masalah dalam kehidupan sosial berdasarkan kondisi realitas yang holistis, kompleks, dan rinci. Oleh karena itu, penulis mengambil metode kualitatif ini untuk mendapatkan informasi yang lebih mengidentifikasikan hal-hal yang akan di lakukan oleh alumni Universitas Tarumanagara dalam melakukan kampanye di Instagram. 
Penulis mengumpulkan data menggunakan dua cara yaitu wawancara dan observasi. Subyek penelitian dalam penelitian ini adalah media sosial Instagram. Sedangkan objek penelitian dalam penelitian ini adalah para alumni Universitas Tarumanagara.

\section{Hasil Temuan dan Diskusi}

Media baru menurut ahli Mark Poster dalam buku The Second Media Age 1990 (2009:413) menandai periode baru di mana teknologi interaktif dan komunikasi jaringan khususnya dunia maya akan merubah masyarakat. Media baru memberikan penggunaan yang terbuka dan fleksibel, tetapi dapat juga memberikan kebingungan dan kekacauan. Perbedaan adalah salah satu nilai besar dalam media baru, tetapi perbedaan juga dapat menyebabkan adanya perpecahan dan pemisahan (2009:414). Sama halnya yang dialami oleh keempat narasumber dalam media baru melalui media sosial.

Dalam penelitian ini, penulis mendapatkan hasil penemuan dengan menggunakan metode wawancara kepada narasumber yang merupakan alumni Universitas Tarumanagara diantaranya adalah : Vincent, Ayu, Jonathan, Samuel dan satu ahli komunikasi politik yaitu Dr. Sudarto ST., M.,Si.

\section{a. Latar Belakang Media Sosial Instagram Terhadap Pemilihan Presiden}

Dari hasil wawancara kepada alumni Universitas Tarumanagara tentang latar belakang media sosial Instagram terhadap pemilihan presiden antara lain alumni pertama yaitu Vincent, menggunakan Instagram untuk berpartisipasi dalam pemilihan presiden dikarenakan Vincent belum mempunyai panggung yang terlalu besar dan juga masih meritis.

Selanjutnya narasumber kedua yaitu Jonathan, menggunakan Instagram sebagai media dalam pemilihan Presiden karena penggunaan Instagram di Indonesia sudah banyak dan meluas.

Narasumber ketiga yaitu Samuel yang menggunakan media sosial untuk mengemukakan pendapat.

Vincent dalam latar belakang media sosial Instagram terhadap pemilihan Presiden mengatakan: "karena saya belum punya panggung yang terlalu besar dan juga masih merintis ya masih baru anak kemarin sore lah, kalo dalam bahasa politik saya lebih bergerak dalam membangun opini di lingkaran saya yaitu teman-teman saya".

Selanjutnya Dr. Sudarto mengatakan: "ya generasi millenial ya sumber informasinya dari Instagram tetapi informasi politik dari Instagram itu terbatas ya dia sifatnya lebih ke fiture ya lebih ke event sedangkan informasi politik seperti itu kurang terakomodir di instagram jadi keterlibatan millenial dalam politik ya kalau di liat dari mediumnya cenderung lebih pasif mereka itu karena fiture-fiture yang ada itu kurang dalam informasi politik dan kurang mengekspresikan dukungan politik gitu. Saya belum melihat terjadi aktivitas politik ya baik pilpres atau dalam isi titik lain di Instagram ya orang lebih menunjukan preferensi politiknya jadi partisipasi Instagram levelnya saya lihat terbatas". 


\section{b. Pengaruh Instagram Terhadap Pemilihan Presiden}

Selanjutnya penulis juga bertanya kepada narasumber tentang pengaruh Instagram terhadap pemilihan presiden kepada Dr. Sudarto., selaku ahli komunikasi politik. "Nah masalah pengaruh ini saya lebih ke komunikasi informal ya kayak alumni dan mahasiswa mereka tidak banyak mempengaruhi lewat media sosial karena mereka cenderung menjaga keharmonisan, kekompakan kelompok".

\section{c. Penggunaan Media Sosial Instagram}

Penggunaan Instagram yang dilakukan oleh narasumber mempunyai alasan tersendiri. Disini penulis menanyakan kepada para narasumber mengenai penggunaan media sosial Insatgram.

Narasumber pertama yaitu Vincent mengatakan: "ya bukan lebih senang ya tapi memang itu adalah wadah yang paling tepat karena penggunanya banyak dan barisan muda untuk seperti kita ini masih banyak menggunakan itu daripada Facebook".

Narasumber kedua yaitu Ayu mengatakan: "karena gimana ya? Instagram kan saat ini lagi mendunia banget ya di manapun di dunia manapun sekarang lagi paling hits tuh instagram ya facebook juga sih, tapi di indonesia mostly instagram, jadi lebih enak koneksi sama temen dan orang lain juga walaupun lebih fokus ke temen".

Narasumber keempat yaitu Jonathan yang mengatakan: "karena Instagram itu cakup anak mudanya banyak banget gitu karena banyak banyak generasi milenial ini kan pemakai sosial media Instagram ini kan cukup banyak tuh di bandingkan orang orang tua. Nah kan banyak banget pendukung pendukung calon-calon pemilihitu memasarkan untuk memperkenalkan kepada anak muda untuk memilih calon presiden yang baik masa depan indonesia".

Pendapat dari ketiga narasumber diperkuat oleh ahli komunikasi politik Dr. Sudarto: "ya betul di dunia di Indonesia sendiri kalo ga salah itu udah nomor dua setelah facebook, facebook masih nomor satu”.

Informasi yang penulis dapatkan dari wawancara dengan para narasumber bahwa penggunaan media sosial Instagram banyak digunakan oleh masyarakat luas terutama generasi milenial, dengan tujuan dan alasan masing-masing, tergantung dari penggunaannya tersebut.

\section{d. Keterlibatan Para Alumni Universitas Tarumanagara dalam Pemilihan Presiden}

Pada bagian ini beberapa alumni Universitas Tarumanagara yang sudah penulis wawancara dan menjadi narasumber mempunyai alasan yang berbeda dalam pemilihan Presiden.

Narasumber yang pertama yaitu Vincent mengatakan: "saya mulai berpartisipasi sejak verifikasi partai. Belum verivikasi calon presiden, tapi verivikasi partai saya sudah mulai ikut berkampanye".

Sedangkan penulis ketika menanyakan kepada narasumber ketiga yaitu Jonathan mengatakan: "sejak pemilihan presiden sebelumnya".

Penulis kembali menekankan pertanyaan yang sama kepada narasumber keempat yaitu Samuel mengatakan : "kalo di bilang mulai sih udah lama banget ya biasanya momen momen tertentu kayak misalnya ada pemilihan presiden segala macem itu kayak dari tahun 2014 terus sekarang 2019 ya biasa pas momen angetnya baru”. 
Ketika penulis menanyakan kepada ahli komunikasi politik sebagai narasumber terakhir yaitu Dr. Sudarto mengatakan:"Ok kalau partisipasi Presiden di Instagram untuk alumni ya saya liat kurang aktif ya kurang aktif dukungan dukungan politiknya kurang terlihat jelas ekspresi politik di Instagram tidak masif tidak menonjol ini bisa dipahami karena pilpres kemarin itukan terjadi fragmentasi sosial yang kuat ya koalisasi politik yang tinggi jadi orang cenderung pilih aman bukan cuman alumni UNTAR aja tapi hampir semua orang cenderung milih aman dia tidak mau terlalu menonjol memperlihatkan dukungan poliiknya karena eksplorasi politik yang tinggi tersebut dan takutnya kalau mereka menunjukan sikap politik yang jelas dan berbeda dengan temannya itu justru menjadi masalah ya, riset saya di presentasi kemarin menunjukan bahwa milenial itu lebih seneng menjaga silence ya lebih di redam tapi ada beberapa yang menunjukan dukungan politiknya tapi tidak terlalu jelas ya misalnya saya liat dia melike figure-figure politik yang dia sukai misalnya di akun instagram Jokowi".

Dari hasil wawancara yang sudah dilakukan oleh penulis mengetahui bahwa keterlibatan para alumni Universitas Tarumanagara dikarenakan berbagai alasan dari internal maupun eksternal.

\section{Simpulan}

Faktor para alumni ikut berpatisipasi memberikan dukungan kepada pemilihan Presiden yaitu dikarenakan ketertarikan dari pribadi mereka terhadap dunia politik maupun tokoh-tokoh politik. Hal ini merupakan hal yang baik karena memungkinkan masyarakat dapat mengeluarkan opini masing-masing. Selain itu, media sosial Instagram merupakan platform yang baik untuk mengungkapkan pendapat para alumni Universitas Tarumanagara, dikarenakan media sosial Instagram merupakan media sosial yang sudah meluas di Indonesia terutama untuk generasi anak muda. Disini penulis menyarankan untuk tetap menjaga keharmonisan tali persaudaraan agar tidak terjadi hal-hal yang tidak diinginkan. Ini semua dilakukan agar dapat memajukan bangsa dan negara, serta memberikan contoh yang baik kepada generasi muda.

\section{Ucapan Terima Kasih}

Penulis berterima kasih kepada Ahmad Junaidi S.S., M.Si., selaku dosen pembimbing serta keluarga teman dan narasumber dan seluruh pihak yang telah membantu penulis dalam menyelesaikan penelitian ini.

\section{Daftar Pustaka}

Cangara, Hafied (2016). Komunikasi Politik. Jakarta : PT Raja Grafindo Persada.

Halim, Rahmawati \& Lalongan, Muhlin. (2016). Partisipasi Politik Masyarakat Teori dan Praktik. Makasar: CV SAH MEDIA.

Little John, Stephen W \& Foss, Karen A. (2009). Teori komunikasi. Jakarta: Salemba Humanika.

Mauludi, Sahrul (2018). Socrates Cafe. Jakarta: PT Elex Media Komputindo.

Nimmo, Dan. (2011). Komunikasi politik. Bandung: PT Remanaja Rosdakarya. 